\title{
ANÁLISE TEMPORAL DOS PROCESSOS EROSIVOS NA MICROBACIA HIDROGRÁFICA DO CÓRREGO DA FAZENDA GLÓRIA, TAQUARITINGA, SP, BRASIL ${ }^{1}$
}

\author{
Flavia Mazzer Rodrigues², Teresa Cristina Tarlé Pissarra ${ }^{3}$ e Sérgio Campos ${ }^{4}$
}

\begin{abstract}
RESUMO - Este estudo teve como principal objetivo avaliar os estados de erosão acelerada do solo da microbacia hidrográfica do córrego da Fazenda Glória, Município de Taquaritinga, SP. Para tanto, foram utilizadas técnicas de sensoriamento remoto e geoprocessamento para análise em fotografias aéreas verticais, coloridas, na escala aproximada de 1:30.000, do aerolevantamento realizado pela BASE - Aerolevantamentos, dos anos de 1983 e 2000. Os processos erosivos foram identificados nas fotografias aéreas da microbacia hidrográfica e observados nas visitas em campo. Como resultado, o aspecto erosivo predominante na área foi o 3, áreas onde ocorria erosão com intensidade que afetava severamente a cobertura vegetal. O estado de erosão 2, com média intensidade, aumentou durante o período analisado. Este trabalho servirá de base para implementar programas de preservação de recursos naturais e de manejo conservacionista na microbacia.
\end{abstract}

Palavras-chave: Sensoriamento remoto, Erosão e Manejo do solo.

\section{TEMPORAL ANALISES OF THE EROSIVE PROCESS AT CÓRREGO DA FAZENDA GLÓRIA WATERSHED, TAQUARITINGA, SP, BRAZIL}

\begin{abstract}
This study had as main objective to evaluate the states of erosion at the Córrego da Fazenda Glória watershed, Taquaritinga, São Paulo State. Remote sensing and GIS ttechniques had been used, in the approach scale of 1:30.000, to analyze the photos from the air survey carried through by BASE -Aerolevantamentos, from 1983 and 2000 years. The map analyses showed the predominant erosive aspect number 3: intensive sheet erosion areas, with common rill. Gully erosion had been seen in the area in the field works. An expressive increase in the erosive aspect 2 along the years instead of erosive aspect 1 was observed. This work will form the basis for implementing programs to preserve natural resources and conservation management in the watershed.
\end{abstract}

Keywords:Remote sensing, Erosion and Soil management.

\section{INTRODUÇÃO}

As ações mundiais para a condução do sistema produtivo em áreas agrícolas e o desenvolvimento de empreendimentos em zonas urbanas têm sido desenvolvidas considerando manejo conservacionista, com proteção dos recursos naturais. Nas ciências ambientais, o estudo do processo erosivo norteia resultados para superfícies onde ocorrem maior desgaste e, ou, arrastamento da terra pela água pluvial, vento, gelo ou outros agentes geológicos, incluindo processos como o arraste gravitacional. Esse processo é um dos principais fenômenos geológicos que acontecem na Terra e ocorrem de várias formas, se forem considerados o seu ambiente geológico e a formação do solo (SILVA et al., 2003).

A evolução dos processos erosivos se dá naturalmente no meio ambiente, de forma lenta e gradual, causando, no decorrer da evolução terrestre, mudanças principalmente no relevo e na vegetação (BERTONI; LOMBARDI NETO, 1990).

\footnotetext{
${ }^{1}$ Recebido em 03.03.2008 e aceito para publicação em 18.04.2011.

${ }^{2}$ Programa de Pós-Graduação em Produção Vegetal pela Universidade Estadual Paulista Júlio de Mesquita Filho, UNESP Jaboticabal, SP, Brasil. E-mail: <flamazzer@hotmail.com>.

${ }^{3}$ Universidade Estadual Paulista Júlio de Mesquita Filho, UNESP - Jaboticabal, SP, Brasil. E-mail: <teresap@fcav.unesp.br>.

${ }^{4}$ Universidade Estadual Paulista Júlio de Mesquita Filho, UNESP - Botucatu, SP, Brasil. E-mail: <seca@fca.unesp.br>.
} 
Diversas metodologias auxiliam na coleta de dados para mensurar o desgaste físico da superfície terrestre. Ahmadi e Mohammadi (2008), Gracia et al. (2005) e Valpreda e Simeoni (2003) identificaram fontes de produção de sedimentos em bacias hidrográficas considerando as características morfométricas e a litologia, no intuito de contribuir para a análise do risco de erosão para aplicação de ações conservacionistas. O trabalho foi desenvolvido na análise de fotografias aéreas e do solo utilizando técnicas de geoprocessamento e possibilitou a identificação das áreas de risco erosivo.

A intervenção humana acelera esses processos erosivos por meio da ocupação e uso intensivo do solo. Quando o solo é protegido por cobertura vegetal densa e com sistema radicular abundante, o processo erosivo é menos intenso (POLITANO et al., 1992). A cobertura vegetal intercepta as gotas de chuva, dissipa a energia cinética da queda e evita o seu impacto direto sobre a superfície, o que reduz o grau de desagregação do solo. A identificação de aspectos erosivos pode ser classificada em alguns grupos, refletindo a importância do tipo de erosão que ocorre na área. A erosão antropogênica, identificada como erosão acelerada (SARAPATKA et al., 2010), remove as camadas superficiais do solo, chegando a formar sulcos e ravinas, quando o escoamento da água é torrencial.

Para estabelecer a prática necessária para cada área de cultivo, são fundamentais as caracterizações do solo, da topografia, da geomorfologia, da hidrologia e da erosão acelerada. As técnicas de sensoriamento remoto servem de ferramenta apropriada para a análise das áreas mais desgastadas e facilitam a elaboração de planos para a prevenção do desgaste nas áreas potencialmente de risco (SARAPATKA et al., 2010). A utilização das informações das fotografias aéreas facilita a reunião dos elementos empregados no planejamento conservacionista (SARAPATKA et al., 2010; AHMADI; MOHAMMADI, 2008; GRACIA et al., 2005; VALPREDA; SIMEONI, 2003).

Este estudo teve como principal objetivo avaliar, por meio de técnicas de sensoriamento remoto, a erosão acelerada do solo em uma microbacia hidrográfica do Município de Taquaritinga, SP, para relacioná-la com as condições das diferentes comunidades vegetais. O resultado servirá de base para a implantação de um manejo conservacionista na área agrícola da microbacia.

\section{MATERIAL E MÉTODOS}

A área de estudo está localizada na porção territorial do Município de Taquaritinga, centro norte do Estado de São Paulo. Apresenta extensão de 2039,32 ha, sua posição geográfica é definida pelas coordenadas: latitudes $21^{\circ} 22^{\prime} 32^{\prime \prime} \mathrm{S}$ e $21^{\circ} 1823^{\prime \prime S}$ e longitudes $48^{\circ} 27^{\prime} 54^{\prime \prime}$ W Gr. e 48 $31^{\prime}$ 51“'W Gr. A Microbacia Hidrográfica do Córrego da Fazenda Glória é uma das áreas hidrográficas mais importantes do município e faz parte da Bacia do Córrego Rico, vinculada ao Comitê de Bacias do Rio Mogi-Guaçu, segundo a Divisão Hidrográfica do Estado de São Paulo (PISSARRA, 2009). O clima é classificado como mesotérmico úmido de verão quente (Cwa). A principal unidade de solo é classificada de acordo com o mapa pedológico do Estado de São Paulo, segundo Oliveira et al. (1999), como argissolos.

O estudo fundamentou-se na análise visual de fotografias aéreas verticais pertencentes ao levantamento de cobertura aerofotogramétrica realizado na região de Ribeirão Preto, dos anos de 1983 e 2000, pela BASE - Aerofotogrametria e Projetos S/A, com escala aproximada de 1:30.000; e em técnicas de geoprocessamento utilizando os sistemas AutoCad para a vetorização dos polígonos a partir da interpretação visual das imagens e ArcGis9 para elaboração das cartas temáticas.

As cartas topográficas da Coleção Cartas do Brasil referentes a mapas originados na região (IBGE, 1971) foram utilizadas como material auxiliar na delimitação e decalque de diversas características da área de estudo, principalmente como ponto de apoio planialtimétrico, da rede de drenagem e da localização da microbacia hidrográfica. Todos os dados foram georreferenciados na Carta para sobreposição e análise dos dados gerados no Sistema de Informação Geográfica - SIG ArcGis9.

A atividade de fotointerpretação foi efetuada por meio da interpretação visual das imagens, sendo em seguida elaborados os mapas temáticos da evolução dos estados de erosão. Todo o trabalho de mapeamento foi acompanhado de visitas em campo durante os anos de 2000 a 2002, confirmando os estados de erosão interpretados nas imagens.

O processamento e edição dos dados foram realizados no SIG ArcGis9. Cada área foi identificada e marcada para verificação em campo. Em campo, nas coordenadas identificadas nas imagens, as práticas

Revista Árvore, Viçosa-MG, v.35, n.3, Edição Especial, p.745-750, 2011 
agrícolas foram anotadas e o estado de erosão, confirmado. Após o processamento das camadas de cada estado de erosão analisado, as áreas menores foram computadas em regiões com outros usos. Os atributos de cada camada (layer) foram identificados e salvos nos formatos shapefile, indicando as áreas dos estados de erosão. A descrição dos estados da erosão acelerada e respectivos padrões fotográficos constam da Tabela 1.

A classificação de erosão não evidente é observada na área onde acontece erosão com intensidade que não afeta perceptivelmente a cobertura vegetal, sem a ocorrência de sinais manifestos de erosão na superfície, excetuando as áreas desprovidas de cobertura vegetal (área onde o solo está sendo preparado para o cultivo agrícola), em que podem ocorrer sulcos superficiais.

Áreas com erosão moderada são aquelas em que a erosão se dá com intensidade que afeta perceptivelmente a cobertura vegetal. Ocorrem sinais manifestos de erosão na superfície que alteram ligeiramente a distribuição, densidade e porte da cobertura vegetal. É comum a ocorrência de erosão em sulcos superficiais e rasos nas áreas com cultura.

Áreas com erosão intensa 1 são aquelas em que ocorre erosão com intensidade que afeta pronunciadamente a cobertura vegetal. Surgem sinais manifestos de erosão na superfície que alteram significativamente a distribuição, densidade e porte da cobertura vegetal. Predomina a erosão laminar severa, em sulcos rasos repetidos ocasionalmente.
Áreas com erosão intensa 2 são aquelas onde ocorre erosão com intensidade que afeta pronunciadamente a cobertura vegetal. Aparecem sinais manifestos de erosão na superfície na forma de sulcos repetidos frequentemente que alteram muito a distribuição, densidade e porte da cobertura vegetal. Predomina a erosão em sulcos profundos repetidos com frequência.

Áreas com erosão muito intensa 3 são aquelas onde ocorre erosão com intensidade que afeta severamente a cobertura vegetal. Surgem sinais manifestos de erosão na superfície, na forma de sulcos profundos repetidos muito frequentemente e há presença de voçorocas.

\section{RESULTADOS E DISCUSSÃO}

Nas fotografias aéreas da tomada fotográfica do ano 2000, as áreas com estados de erosão acelerada aparecem como sulcos em tonalidades mais claras, geralmente crescentes dos topos em direção aos vales. Essa tonalidade reflete a exposição do subsolo e contrasta com o tom mais escuro dos locais preservados.

As áreas de voçorocas foram determinadas nas visitas em campo na região da bacia hidrográfica. Essas área não foram identificadas nas fotografias aéreas, tendo em vista a cobertura vegetal ao redor das voçorocas, a qual não possibilitou a interpretação visual na imagem.

A análise das cartas temáticas geradas, indicando os aspectos erosivos observados em 1983 e 2000 (Figuras 1 e 2), permite identificar áreas mais suscetíveis aos processos erosivos.

Tabela 1 - Padrões fotográficos dos estados da erosão acelerada, Município de Taquaritinga, SP. Table 1 - Photographic standards of the states of the erosion, Taquaritinga County, SP.

\begin{tabular}{|c|c|}
\hline Estado de erosão acelerada & Padrão fotográfico \\
\hline 0 - Não evidente & $\begin{array}{l}\text { Sem alterações da imagem relacionada com a erosão acelerada em áreas } \\
\text { de preservação natural }\end{array}$ \\
\hline $\begin{array}{l}1 \text { - Área com erosão } \\
\text { até moderada }\end{array}$ & Tonalidade mais clara, geralmente associada a topos e meia- encosta. \\
\hline $\begin{array}{l}2 \text { - Áreas com erosão intensa } 1- \\
\text { sulcos raros ou ocasionais }\end{array}$ & $\begin{array}{l}\text { Alterações típicas relacionadas com a presença de sulcos (filamentos no sentido } \\
\text { do declive com tonalidade amarelada e textura alterada com pouca frequência). }\end{array}$ \\
\hline $\begin{array}{l}3 \text { - Áreas com erosão intensa } 2 \text { - } \\
\text { sulcos comuns }\end{array}$ & $\begin{array}{l}\text { Alterações típicas relacionadas com a presença de sulcos e a remoção de camadas } \\
\text { finas em áreas extensas das partes declivosas do terreno (filamentos no sentido } \\
\text { do declive com tonalidade e textura alterada com muita frequência). }\end{array}$ \\
\hline 4 - Voçorocas & $\begin{array}{l}\text { Alterações típicas evidenciando a presença de sulcos profundos, canais no sentido } \\
\text { do declive, formam traços sinuosos, espessos e irregulares, tonalidade bastante clara, } \\
\text { contrastando com tons escuros de traços evidenciados na fotografia área. Área } \\
\text { sem cobertura vegetal. }\end{array}$ \\
\hline 5 - Sulco e Ravina & $\begin{array}{l}\text { Alterações típicas evidenciando a presença de erosão (canais no sentido do declive, } \\
\text { com ou sem presença de sulcos). }\end{array}$ \\
\hline
\end{tabular}



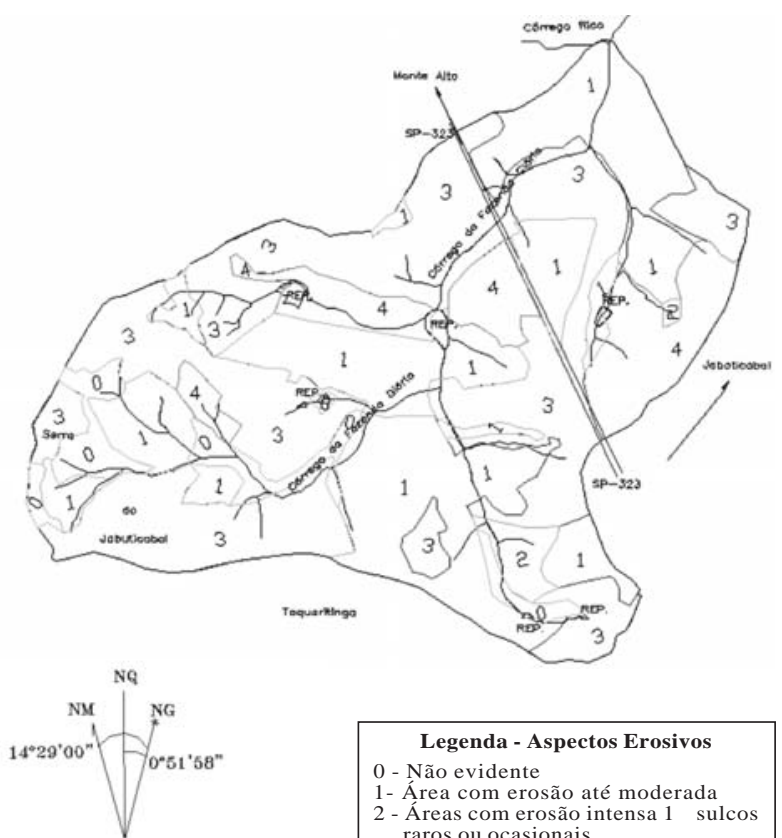

Declinaça Magnetics $197 \%$ Centro dae Folha de Taquaritinga

Figura 1 - Mapa temático dos aspectos erosivos da Microbacia Hidrográfica do Córrego da Fazenda Glória, Município de Taquaritinga, SP, 1983.

Figure 1-Map of the erosive aspects of watershed Córrego da Fazenda Glória, Taquaritinga County, SP, Brazil, 1983.

A distribuição da extensão da abrangência dos estados de erosão (Tabela 2) da Microbacia Hidrográfica do Córrego da Fazenda Glória durante o período analisado indica a potencialidade que esse mapeamento apresenta em termos de fiscalização ambiental no que tange à legislação brasileira de conservação do solo.

O impacto causado no meio é descrito nos aspectos erosivos em locais que trazem como atividade principal a agricultura intensiva em cobertura vegetal como canade-açúcar e cultura de citrus. Os processos hidrológicos associados ao uso e manejo da terra claramente exercem papel dominante na produção e transporte de sedimentos, o mesmo verificado por Ahmadi e Mohammadi (2008), Gracia, et al. (2005), Valpreda e Simeoni (2003) e Machado e Vettorazzi (2003).

Tem-se observado, ao longo dos anos, aumento significativo no estado de erosão intensa 1: sulcos raros ou ocasionais em detrimento do estado de erosão
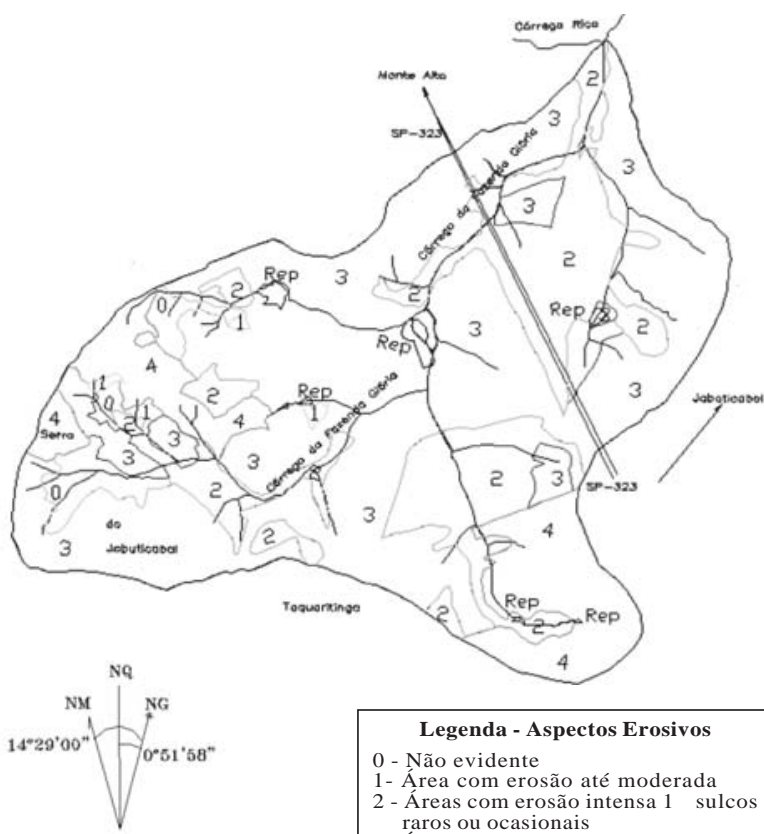

Declinaecão Magnetics 1972 Centro da Folha de Taquariting

\begin{tabular}{|l|}
\hline \multicolumn{2}{|c|}{ Legenda - Aspectos Erosivos } \\
0 - Não evidente \\
1- Área com erosão até moderada \\
2 - Áreas com erosão intensa 1 sulcos \\
raros ou ocasionais \\
3- Áreas com erosão intensa 2 sulcos \\
comuns \\
4- Voçorocas \\
5 - Sulco e ravina \\
\hline
\end{tabular}

Figura 2 - Mapa temático dos aspectos erosivos da Microbacia Hidrográfica do Córrego da Fazenda Glória, Município de Taquaritinga, SP, Brasil, 2000.

Figure 2-Map of the erosive aspects of watershed Córrego da Fazenda Glória, Taquaritinga County, SP, Brazil, 2000.

laminar: ligeira/moderada. Esse cenário reflete a diferença entre o impacto causado anteriormente nas práticas agrícolas e nos processos naturais e a crescente perda de solo no meio.

Os estados de erosão intensa 2: sulcos comuns e erosão muito intensa 3: sulcos frequentes/muito frequentes também foram crescentes, refletindo o manejo inadequado na área e a suscetibilidade ao processo erosivo mais intenso. Tal fato foi observado, principalmente, nas áreas a montante da microbacia, em relevos mais acidentados.

É importante ressaltar que áreas de vegetação nativa ao redor de algumas nascentes permitem maior proteção dos impactos das gotas da chuva no solo. Entretanto, ainda se verificam, nos trabalhos em campo, sulcos ocasionais nos períodos de maior precipitação. Esse fator pode indicar maior produção de sedimento nos cursos d'água ao longo do período de chuva, entre os meses de novembro a março.

Revista Árvore, Viçosa-MG, v.35, n.3, Edição Especial, p.745-750, 2011 
Tabela 2 - Distribuição da extensão da abrangência dos aspectos erosivos da Microbacia Hidrográfica do Córrego da Fazenda Glória, Taquaritinga, SP, 1983 e 2000.

Table 2 - Extension area of the erosive aspects of Córrego da Fazenda Gloria watershed, Taquaritinga, SP, Brazil, 1983 and 2000.

\begin{tabular}{|c|c|c|c|c|}
\hline \multirow[t]{2}{*}{ Aspectos erosivos - Estados de erosão acelerada } & \multicolumn{2}{|c|}{ Tomadafotográfica 1983} & \multicolumn{2}{|c|}{ Tomadafotográfica 2000} \\
\hline & ha & $\%$ & ha & $\%$ \\
\hline 0. Não evidente & 230,9 & 11,32 & 67,95 & 3,33 \\
\hline 1. Erosão laminar: ligeira/moderada & 847,70 & 41,57 & 12,78 & 0,63 \\
\hline 2. Erosão intensa 1: sulcos raros ou ocasionais & 37,36 & 1,83 & 457,2 & 22,42 \\
\hline 3. Erosão intensa 2: sulcos comuns & 882,0 & 43,25 & 1208,88 & 59,28 \\
\hline 4. Erosão muito intensa: sulcos frequentes/muito frequentes & 235,20 & 11,53 & 292,5 & 14,34 \\
\hline 5. Voçorocas & 0 & 0 & 0 & 0 \\
\hline TOTAL & 2039,31 & 100,00 & 2039,31 & 100,00 \\
\hline
\end{tabular}

O principal resultado foi identificar o conhecimento das áreas mais suscetíveis ao processo erosivo, no intuito de propor alternativas para reduzir o impacto com práticas agrícolas mais adequadas ao sistema de manejo conservacionista. Essa análise foi realizada na observação do potencial para diminuir a perda de solo (SARAPATKA et al., 2010).

Em algumas áreas, os resultados da interpretação visual nas imagens tratadas no SIG não condiziam com a realidade local. Sugere-se, portanto, a confirmação dos padrões fotográficos em campo.

Nessas áreas, recomendam-se práticas conservacionistas atentando para a importância de reduzir a perda de solo e, consequentemente, aumentar o fornecimento de nutrientes para as plantas. O grande potencial dos sistemas agroflorestais é uma estratégia para conservação dos solos em microbacias (FRANCO et al., 2002).

Outro fato observado em campo foi a mudança de cobertura vegetal para a cultura de cana-de-açúcar em detrimento da cultura de citrus e goiaba. Esse fato pode ter ocasionado mudanças nas práticas agrícolas e proporcionado maior revolvimento do solo e a sua consequente perda nos processos erosivos mais acentuados, como verificado nas análises visuais e em campo. Conforme trabalhos desenvolvidos por Ribeiro et al. (2007), nessas áreas pode-se recomendar o sistema agrossilvipastoril para minimizar o processo erosivo, tendo em vista a suscetibilidade ao processo erosivo e o manejo realizado em pequenas propriedades rurais.

\section{CONCLUSÕES}

O aspecto erosivo predominante é o 3. As voçorocas foram encontradas na área da microbacia hidrográfica nas visitas em campo, não sendo identificadas nas fotografias aéreas, tendo em vista a cobertura vegetal. Ocorreu aumento expressivo no aspecto erosivo 2 ao longo dos anos em detrimento do aspecto erosivo 1 , que anteriormente prevalecia na área.

\section{REFERÊNCIAS}

AHMADI, H.; MOHAMMADI, A. A.

Identification of critical sediment source areas at regional scale for environmental management (case study: Dehnamak Basin, Iran). Desert, v.14, n.1, p.119-125, 2009.

BERTONI, J.; LOMBARDI NETO, F.

Conservação do solo. São Paulo: Ícone, 1990. 355p.

FRANCO, F. S. et al. Quantificação de erosão em sistemas agroflorais e convencionais na Zona da Mata de Minas Gerais. Revista Árvore, v.26, n.6, p.751-760, 2002 .

INSTITUTO BRASILEIRO DE GEOGRAFIA E ESTATÍSTICA - IBGE. Geociências. CartografiaDocumentos cartográfico. Carta do Brasil, escala 1:50.000. 1972.

GRACIA, F. J. et al. Monitoring coastal erosion at different temporal scales on sandy beaches: application to the Spanish Gulf of Cadiz coast. Journal of Coastal Research, v.49, Special Issue, p.22-27, 2005. 
MACHADO, R. E.; VETTORAZZI, C. A..

Simulação da produção de sedimentos para a microbacia hidrográfica do Ribeirão dos Marins (SP). Revista Brasileira Ciência do Solo. v.27, n.4, p.735-741, 2003.

OLIVEIRA, J. B. et al. Mapa pedológico do Estado de São Paulo: Legenda expandida. Campinas: Instituto Agronômico/Embrapa Solos, 1999. 64p

POLITANO, W. Estudo da adequabilidade do emprego de bacias hidrográficas de $3^{a}, 2^{a}, 1^{a}$ ordem de magnitude na análise morfométrica aplicada a solos. 331f. Tese (Livre-Docência em Topografia e Fotogrametria) - Faculdade de Ciências Agrárias e Veterinárias, Universidade Estadual Paulista, Jaboticabal, 1992.

PISSARRA, T.C.T. et al. Informações básicas para o planejamento ambiental: Município de Jaboticabal/Coord. Secretaria Municipal de Agricultura, Abastecimento e Meio Ambiente de Jaboticabal. Jaboticabal: Funep, 2009. p.70.
RIBEIRO, S. C. et al. Estimativa do abatimento de erosão aportado por um sistema agrossilvipastoril e sua contribuição econômica. Revista Árvore, v.31, p. 285-293, n.2, 2007.

SARAPATKA, B.; BEDNAR, M.; NOVAK, P. Analysis of soil

degradadtion in the Czech Republic: GIS approach. Soil and Water Resources, v.3, p.108-112, 2010.

SILVA, A. M.; SCHULZ, H. E.; CAMARGO, P. B. Erosão e hidrossedimentologia em bacias hidrográficas. São Carlos: Rima, 2003. 138p.

VALPREDA, E.; SIMEONI, U. Assessment of coastal erosion susceptibility at the national scale: The Italian case. Journal of Coastal Conservation, v.9, n.1, p.43-48, 2003. 